\title{
London's Zoo
}

London's Zoo. (An Anthology to Celebrate 150 Years of the Zoological Society of London, with its Zoos at Regent's Park in London and Whipsnade in Bedfordshire.) Compiled by Gwynne Vevers. Pp. 159. (Bodley Head: London, Sydney and Toronto, April 1976.) £4.95.

What a great deal of fun Dr Gwynne Vevers must have experienced sifting through the enormous amount of material available to him and what o frustrations he must have experienced when it came to editing, perhaps one should say culling, the plethora of $\infty$ quotable quotes that he must have gathered together. While reading the book one soon becomes aware of the careful thought which has gone into the form of presentation. Inevitably he has concentrated on the early days, days when the foundations of the Zoological Society of London were being laid with a clear emphasis on the advancement of zoological science and the development of a living collection of animals. In those days creatures arriving at the Society's premises might be found in a crate, a jar of spirit, or just a package of skin and skeleton for examination by the early zoological researchers. The Society's museum was consolidated in 1849 with the

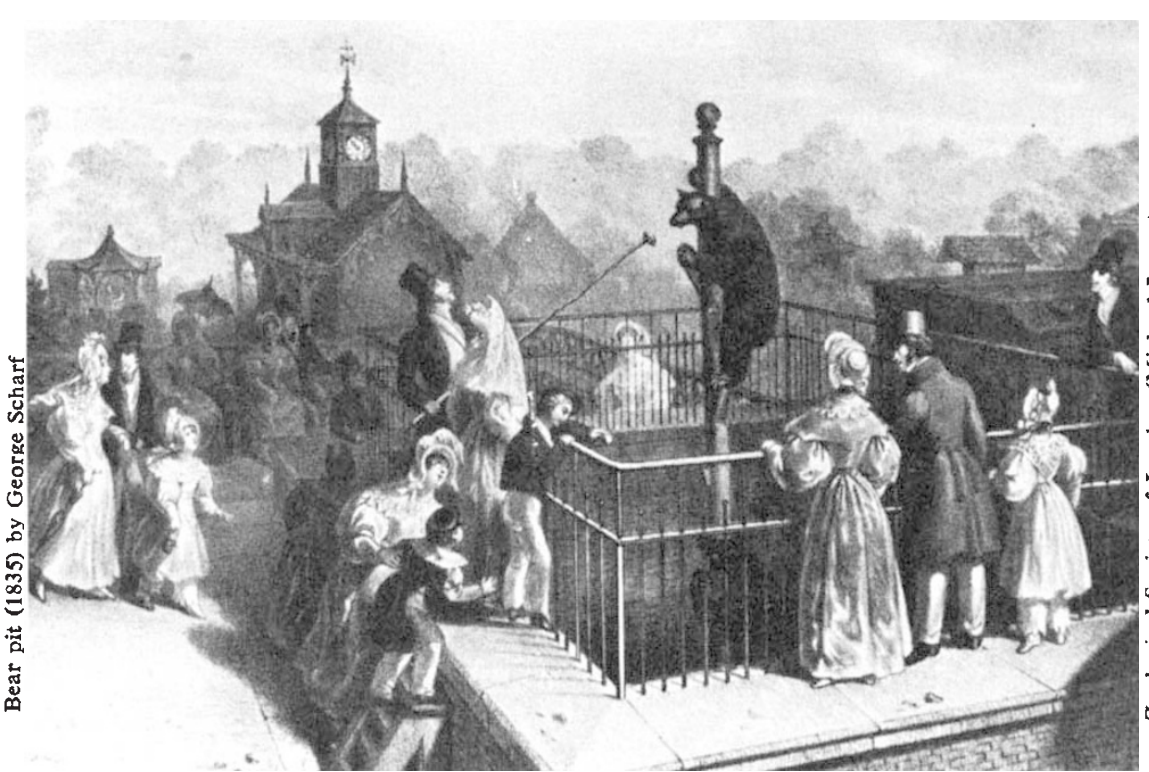

Zoology Department of the British Museum, and since that date material available as a result of deaths in the animal collection has gone to this museum.

It was this insistence by the founding fathers on a scientific approach to the development of its collection that has resulted in the Society being held in the highest esteem in the zoological world. But to the millions of visitors who have visited the animal collection over the years it has been the "Zoo", a place to wonder at strange creatures, to be amused, to recreate, to escape for a moment from the sometimes harsh realities of everyday existence.

The anthology is the Zoo itself, it involves animals and people, ideas and ideals, the serious, the flippant, the scientific and the anthropomorphic. It should make good and enjoyable reading for all who have a specific or passing interest in the growth and development of this great Zoological Society and its Zoo.

R. J. Wheater

\section{Lovell on Blackett}

P. M. S. Blackett: A Biographical Memoir. By Sir Bernard Lovell. Pp. 115. (Royal Society: London, 1976.) UK £4; Overseas $£ 4.10$.

TH1S book is a reprint of Bernard Lovell's account of Lord Blackett published recently in the Biographical Notices of the Royal Society. These Notices are accounts of recently deceased scientists written by their friends. They are of very great interest now and will be invaluable to historians in the future. Regrettably few libraries, especially in the US, subscribe to the series. The Royal Society wisely insists that the Notices be written within a few months of the subject's death and usually gets an account that bears the impress of friendship and of recent memories of personality and oddities of character.

It is not easy to write a biographical notice: on the one side there is the pressure of friends, relations, and often of the widow, to omit anything at all colourful (a widow once insisted that $\frac{\tilde{m}}{m}$ I omit the fact that a man had died of 0 a stomach haemorrhage after a lunch

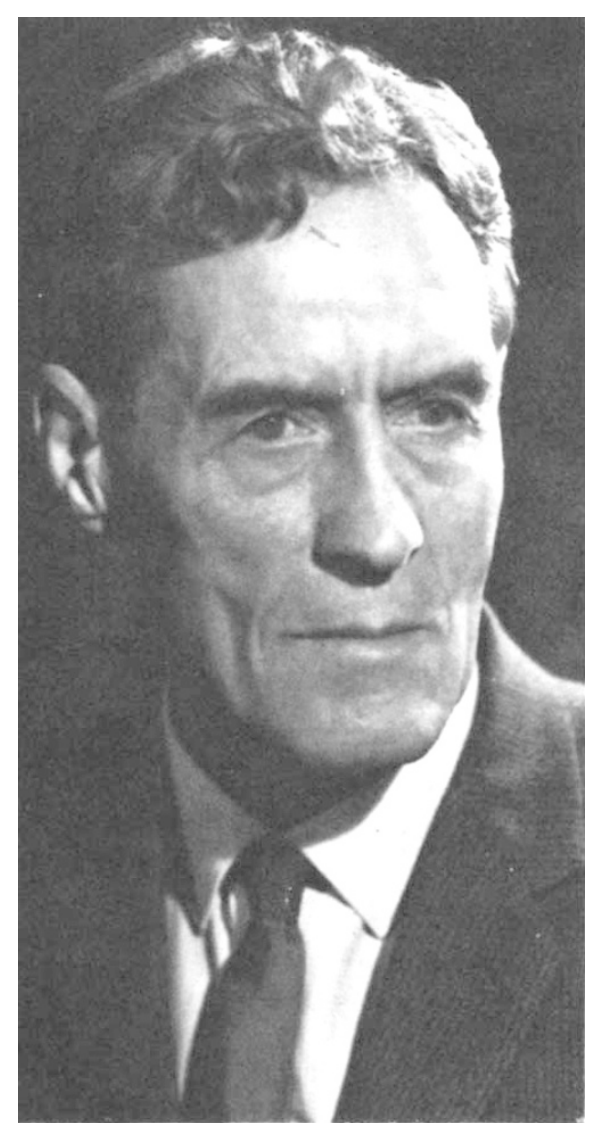

to celebrate his 90 th birthday). On the other side there is the difficulty of giving a realistic account of scientific innovation and its attendant struggles, a thing done with such éclat by James Watson, and above all of letting the character emerge from action and anecdote rather than from explicit description.

In writing of Patrick Blackett all these difficulties are magnified by the immense achievement. The writer could easily be overwhelmed by the ramifications of the three careers, in science, in warfare and in politics and by the major achievements in three fields of science-nuclear physics, cosmic rays and geomagnetism. In fact Lovell has done it superbly well. The account is beautifully clear and readable, and Blackett emerges from it as the uniquely intelligent and humane figure that he was. It is a book that every young physicist should own and that no-one who knew Patrick could possibly be without. The immense care that has gone into getting it all right has been enormously worthwhile. This is how Blackett appeared to his contemporaries and anyone who writes about him in the future must rely largely on this.

Edward Bullard 